\title{
PERENCANAAN GEDUNG KELAS SEBAGAI TAMPAK DEPAN KOMPLEKS SMK WIDYA DHARMA, TUREN
}

\author{
Gaguk Sukowiyono \\ Dosen Prodi Arsitektur, Fak. Teknik Sipil dan Perencanaan, ITN Malang \\ e-mail: gaguksukowiyono@yahoo.com \\ Debby Budi Susanti \\ Dosen Prodi Arsitektur, Fak. Teknik Sipil dan Perencanaan, ITN Malang \\ e-mail: budisusantidebby@gmail.com \\ Breeze Maringka \\ Dosen Prodi Arsitektur, Fak. Teknik Sipil dan Perencanaan, ITN Malang
}

\begin{abstract}
ABSTRAK
SMK Widya Dharma yang terletak di Jl. Dharmawangsa, Desa Talok, Kecamatan Turen, Kabupaten Malang merupakan sekolah kejuruan dengan jurusan komputer yang terakreditasi $A$. Jumlah siswa baru yang masuk setiap tahunnya terus meningkat, akibatnya perlunya adanya penambahan ruang kelas dan fasilitas pendukung lainnya, seperti: ruang praktikum, aula, tempat parkir, lapangan olahraga, dan sebagainya. Berdasarkan data kondisi tapak yang ada diperlukan pendampingan dalam upaya perencanaan penambahan gedung kelas sekaligus perencanaan masterplan kompleks sekolah tersebut.
\end{abstract}

Kata kunci : penataan tapak, desain bangunan, identitas

\begin{abstract}
Widya Dharma Vocational School, located on Jl. Dharmawangsa, Talok Village, Turen Subdistrict, Malang Regency is a vocational school with accredited computer majors $A$. The number of new students entering each year continues to increase, as a result the need for additional classrooms and other supporting facilities, such as practicum rooms, halls, parking lots, sports fields, and so on. Based on existing site condition data, assistance is needed in planning the addition of classrooms as well as planning the school complex master plan.
\end{abstract}

Keywords : site plan, building design, identity

\section{PENDAHULUAN}

Perguruan tinggi berkewajiban menyelenggarakan pengabdian kepada masyarakat disamping melaksanakan pendidikan sebagaimana diamanahkan oleh Undang-undang Nomor 20 Tahun 2003 tentang Sistem Pendidikan Nasional Pasal 20. Sejalan dengan kewajiban tersebut, Undangundang Nomor 12 Tahun 2012 tentang Pendidikan Tinggi Pasal 45 menegaskan bahwa pengabdian masyarakat di perguruan tinggi diarahkan 
untuk mengembangkan ilmu pengetahuan dan teknologi, serta meningkatkan kesejahteraan masyarakat dan daya saing bangsa. Dalam pasal tersebut juga ditegaskan bahwa pengabdian kepada masyarakat merupakan kegiatan civitas akademika dalam mengamalkan dan membudayakan ilmu pengetahuan dan teknologi untuk memajukan kesejahteraan umum dan mencerdaskan kehidupan bangsa.

SMK Widya Dharma terletak di jalan Dharmawangsa masuk dalam wilayah Desa Talok, Kecamatan Turen, Kabupaten Malang merupakan sekolah kejuruan swasta yang memiliki jurusan komputer yang sekolahnya sudah terakreditasi $A$. Jumlah siswa barunya yang masuk setiap tahunnya terus mengalami peningkatan yang cukup tinggi. Hal ini berakibat pada kurangnya sarana dan prasarana yang ada, sehingga perlunya adanya penambahan ruang kelas dan fasilitas pendukung lainnya, seperti: ruang praktikum, ruang aula, tempat parkir, lapangan olahraga, tempat dudukduduk untuk diskusi tugas, ruang pelayanan administrasi, dan sebagainya.

Tapak yang dipunyai SMK ini berbentuk persegi panjang kearah Utara-Selatan dengan ukuran lebar \pm 41.96 meter dan panjang \pm 213.30 meter. Lokasi tapak di kelilingi persawahan dan perkebunan. Sisi depan sekolah terdapat jalan desa dengan lebar \pm 4.00 meter dan sisi belakang terdapat lahan kosong dan jalan propinsi yang berjarak \pm 100 meter dari lokasi sekolah. Pada lahan kosong ini rencananya akan dibangun kompleks perumahan secara keseluruhan sehingga secara tidak langsung bahwa hal ini akan berdampak pada tertutupinya lokasi sekolahan. Untuk meminimalisir permasalahan tersebut, maka perlu adanya suatu desain rancangan sekolahan yang dapat dijadikan sebagai landmark lingkungan yang sekaligus dapat dijadikan sebagai identitas agar mudah dikenali.

\section{TINJAUAN PUSTAKA}

\subsection{Gedung Kelas, Gedung Laboratorium, dan Gedung Parkir}

\section{a. Gedung Kelas}

Desain interior ruang pembelajaran sangat tergantung pada jenis dan karakteristik sekolahnya. Ruang pembelajaran hendaknya disesuaikan situasinya dengan jenis atau bidang studinya dan hendaknya dapat diubah dan diatur ulang setiap saat secara mudah dan cepat sesuai kebutuhan, terutama pergantian susunan meja kursi.. Di dalam desain interior ada prinsip-prinsip umum yang dapat diberlakukan dalam penataan interior ruang kelas. Prinsip-prinsip tersebut adalah: (1) kesatuan; (2) keseimbangan; (3) proporsi; dan (4) Kontras.

Desain interior ruang pembelajaran juga merupakan proses kreatif, artinya seorang desainer harus memiliki kreativitas untuk menciptakan 
bentuk-bentuk visual yang dalam perkembangan terbaru harus disesuaikan dengan pemakaian teknologi baru (http://www.arts.ohio-state.edu/design ).

Bentuk dan dimensi ruang kelas sangat berpengaruh terhadap fleksibilitas dan adaptabilitas. Untuk mencapai efektivitas pembelajaran, bentuk dan dimensi ruang kelas perlu dirancang dengan memperhitungkan aspek ergonomi dan antropometri. Ergonomi dan antropometri mempunyai arti penting dalam perancangan desain interior. Oleh karena itu, dengan memperhatikan faktor-faktor tersebut maka para pemakai ruang akan mendapatkan produktifitas dan effisiensi kerja yang berarti suatu penghematan dalam penggunaan ruang. Ergonomi adalah ilmu yang mempelajari kondisi fisik seseorang dalam melakukan kerja, yakni meliputi: (1) keja fisik; (2) efisiensi kerja; (3) tenaga yang dikeluarkan untuk suatu objek; (4) konsumsi kalori; (5) kelelahan; dan (6) pengorganisasian sistem kerja. Sedangkan antropometri adalah proporsi atau dimensi tubuh manusia beserta sifat-sifat karakteristik fisiologis serta kemampuan relatif dari kegiatan manusia yang saling berbeda dalam lingkungan mikro (Pramudji Suptandar, 1995: 19-20).

\section{b. Gedung Laboratorium}

Payung hukum yang memayungi masalah standar laboratorium sekolah adalah Peraturan Menteri Pendidikan Nasional (Permendiknas) No. 24 Tahun 2007 yang mengatur tentang standar sarana dan prasarana sekolah termasuk di dalamnya laboratorium komputer. Peraturan ini mengatur seluk beluk tentang bagaimana sebuah laboratorium sekolah yang seharusnya ada dan dikembangkan oleh sekolah. Berdasar pada Permendiknas No. 24 Tahun 2007, setiap laboratorium komputer yang ada di sekolah SMP, SMA, MTS, MA dan SMK harus memenuhi kriteria - kriteria yang telah disebutkan pada peraturan ini.

\section{c. Gedung Parkir}

Penempatan fasilitas parkir di dalam bangunan, baik pada sebagian bangunan pada basemen,maupun pada bangunan khusus parkir, ditetapkan sebagai berikut :

1. Tinggi minimum ruang bebas struktur (head room) untuk ruang parkir adalah $2.25 \mathrm{~m}$.

2. Setiap lantai parkir harus memiliki sarana untuk sirkulasi horizontal dan atau sirkulasi vertical untuk orang dengan ketentaun bahwatangga spiral dilarang digunakan .

3. Lantai untuk parkir luasnya mencapai $500 \mathrm{~m}^{2}$ atau lebih harus dilengkapi ramp naik dan turun masing-masing 2 unit . 
4. Bangunan parkir yang menggunakan ramp spiral, diperkenakan maksimal 5 lantai.

5. Lebar ramp lurus satu arah minimum $3.00 \mathrm{~m}$ dan untuk dua arah harus terdapat pemisah minimum selebar $0.50 \mathrm{~m}$ sehingga lebar minimum berjumlah $6.5 \mathrm{~m}$

6. Ketentuan ramp pada bangunan parkir adalah sebagai berikut;

- Kemiringan ramp lurus bagi jalan kendaraan pada bangunan parkir maksimal 1 berbanding 7

- Apabila lantai parkir mempunyai sudut kemiringan,maka sudut kemiringan tersebut maksimal 1 berbanding 20.

- Pada ramp lurus jalan satu arah, lebar minimal $3 \mathrm{~m}$ dengan ruang bebas struktur di kanan kiri minimal $60 \mathrm{~m}$.

- Pada ramp melingkar jalan satu arah, lebar jalan minimal $3.6 \mathrm{~m}$ dan untuk dua arah lebar jalan minimal $7 \mathrm{~m}$ dengan pembatasan jalan lebar $50 . \mathrm{cm}$, tinggi minimal $10 \mathrm{~cm}$

- Jari-jari tengah ramp melingkar minimal $9 \mathrm{~m}$ di hitung dari as jalan terdekat.

\section{METODE PENELITIAN}

Pada kegiatan pengabdian masyarakat ini metode pengumpulan data didapatkan dengan cara sebagai berikut :

- Observasi

Yaitu mendapatkan data dari lapangan dengan cara mendatangi langsung objek rancangan kemudian mencatat informasi sebagaimana yang kami saksikan selama berada di lokasi dalam hal ini guna mempelajari secara langsung bagaimana keadaan pada lapangan.

- Wawancara (interview)

Selama observasi dilakukan kami juga melakukan wawancara dan komunikasi kepada Kepala Sekolah maupun Staf SMK Widya Dharma Turen agar kami dapat mengambil keputusan dalam merancang sesuai tuntutan klien.

Setelah mendapatkan data-data yang diperlukan dalam kegiatan ini, tahap selanjutnya adalah analisa data yang dilakukan dengan cara sebagai berikut : 


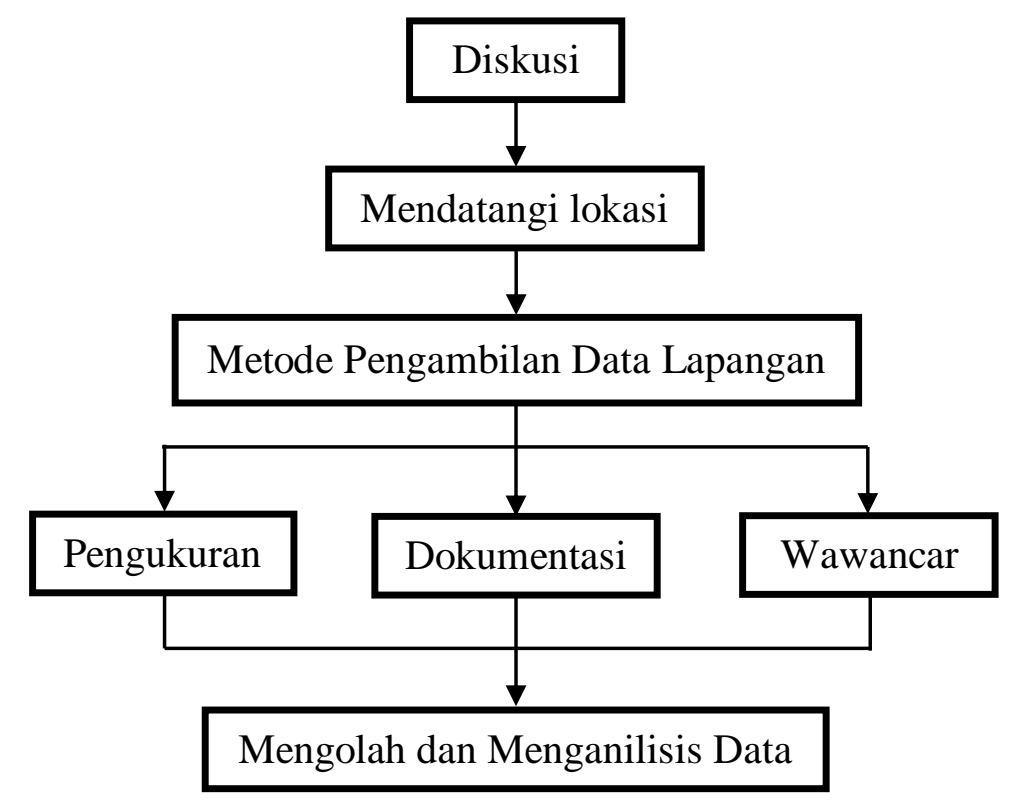

\section{HASIL DAN PEMBAHASAN}

\section{a. Gedung Kelas}

Objek gedung kelas baru yang akan dibangun ini untuk memenuhi kebutuhan akan kurangnya kelas untuk proses belajar mengajar pada SMK Widya Dharma Turen, pihak sekolah berencana untuk membangun sebuah gedung pada depan wilayah sekolah sekaligus menjadikan sebuah daya Tarik bagi siapapu yang akan melewati di depan sekolah, dan lahan yang disediakan oleh pihak sekolah adalah $8 \mathrm{~m} \times 39,5 \mathrm{~m}$.

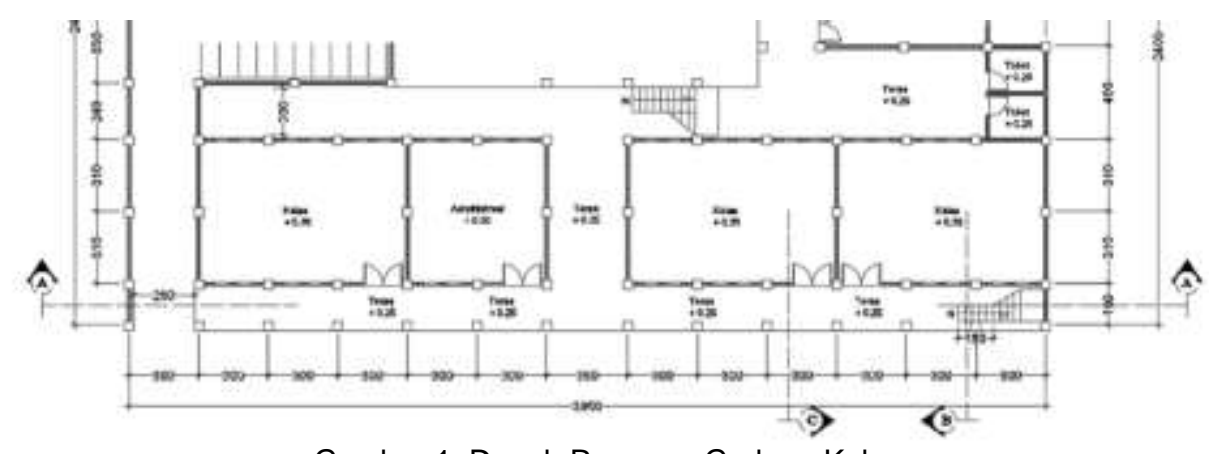

Gambar 1 Denah Rencana Gedung Kelas 
Penggunaan kacajuga pada fasede memberikan kesan modern pada bangunan
Ada area drop off atau teras bangunan yang sengaja dibuat agar menjadi vocal point pada bangunan menggunakan material ACP (Aluminium Composite Panel)

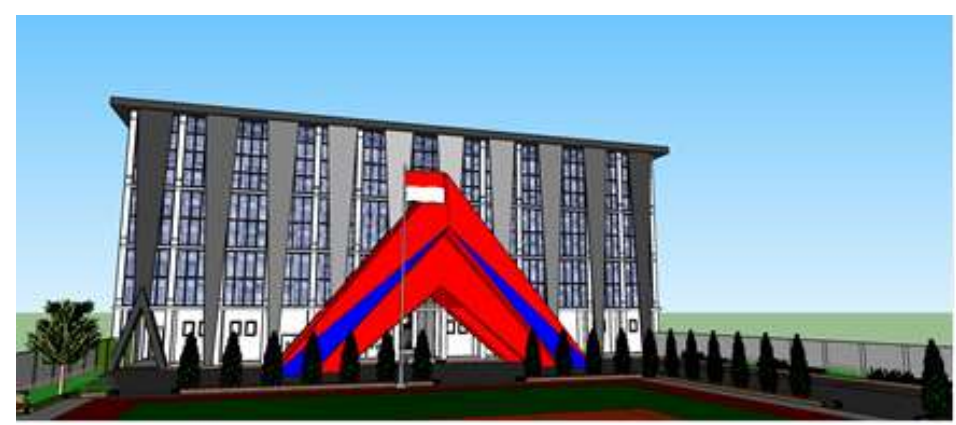

Gambar 2 Rencana Tampak Depan Gedung Kelas

\section{b. Gedung Laboratorium}

Dikarenakan pada waktu survei langsung ke lapangan, sebagian dari gedung kelas telah dikerjakan. Dimana pondasi pada bagian kelas tersebut naik $30 \mathrm{~cm}$. Oleh karena itu, lantai dasar gedung lab juga naik $30 \mathrm{~cm}$ agar terlihat menyatu dengan gedung kelas, selain itu juga sebagai batas antara area gedung dan ruang terbuka disekitarnya. Namun pada bagian teras gedung hanya naik $25 \mathrm{~cm}$ agar terlihat area teras dan area dalam ruangan lab. Diberi juga tangga sebagai sirkulasi vertical antara dasar tanah dan teras.

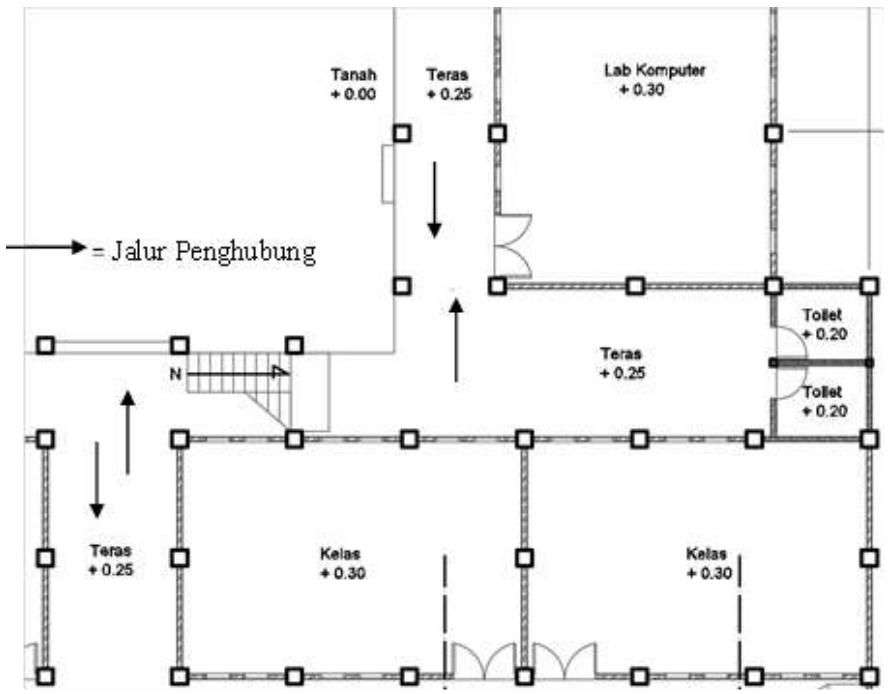

Gambar 3 Denah Rencana Ruang laboratorium 
Dengan ukuran $7.2 \times 12 \mathrm{~m}$ dan jumlah lantai 3 serta terdapat sirkulasi penghubung antara Gedung kelas dan Gedung lab di setiap lantainya membuat rancangan terlihat menyatu dan padu, tidak terlihat seperti Gedung yang terpisahs. Ditambah adanya toilet di setiap lantai juga membuat rancangan telah sesuai dengan yang dimintai dari pihak sekolah.

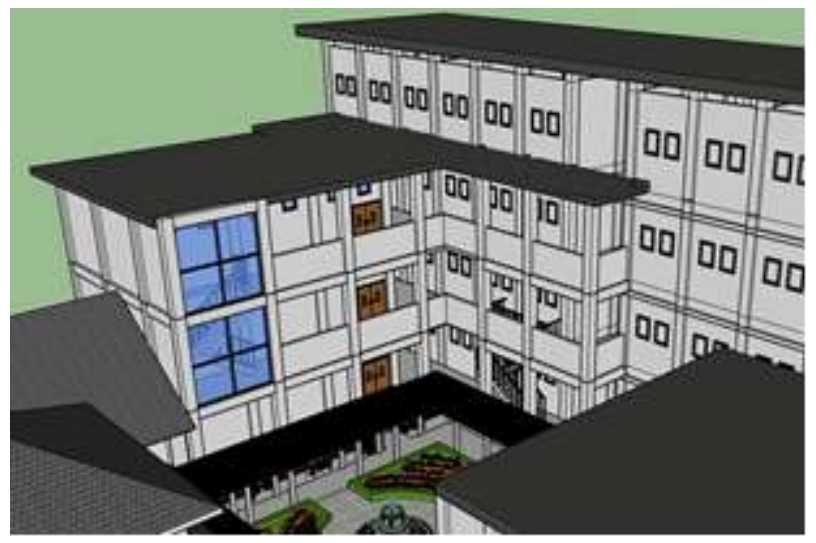

Gambar 4 Rencana Tampilan Bangunan Gedung Laboratorium

\section{c. Gedung Parkir}

Hasil rancangan bangunan gedung parkiran ini dikhususkan untuk sepeda motor dengan ukuran denah 11,50 meter x 13.55 meter berlantai 3 dengan kapasitas 90 motor.

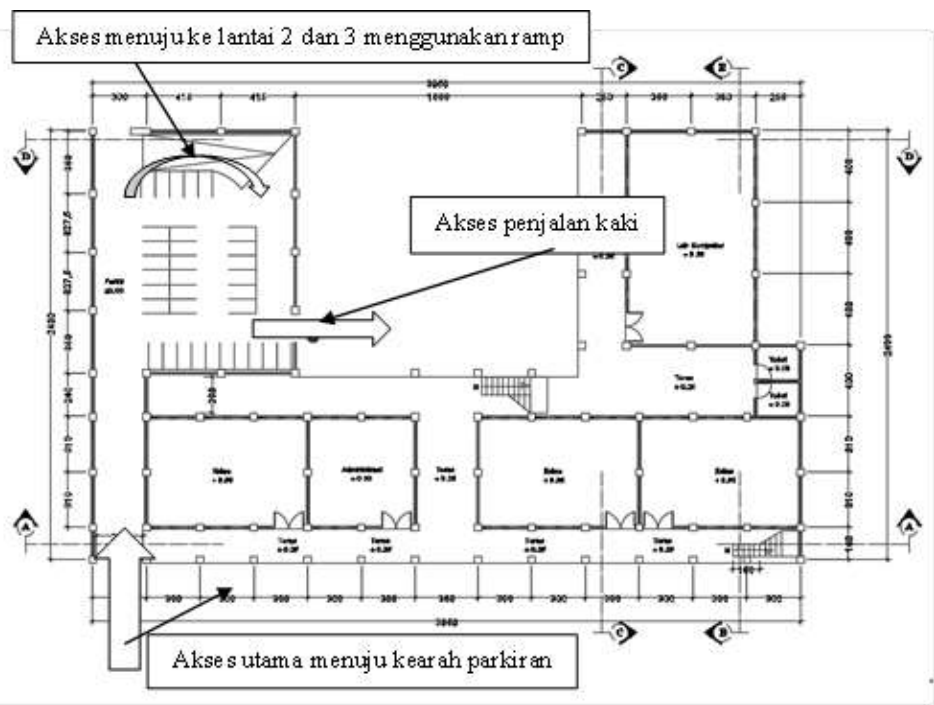

Gambar 5 Denah Rencana Gedung Parkiran 

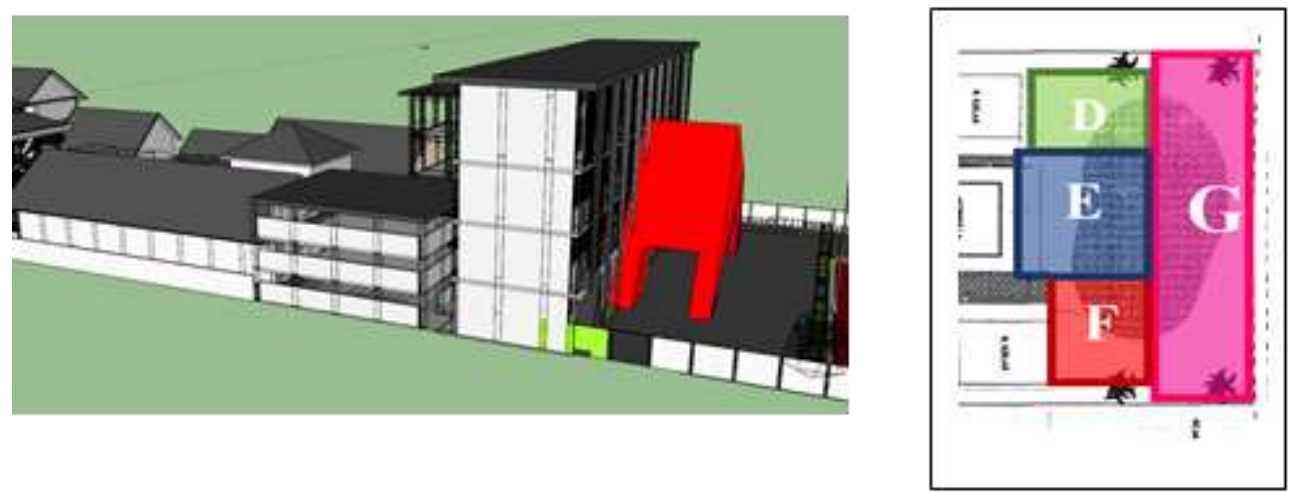

Gambar 6 Rencana Gedung Parkiran

\section{KESIMPULAN}

Perencanaan sebuah bangunan sekolah selain harus memperhatikan kondisi tapak dan eksistingnya, juga harus memperhatikan studi perilaku terhadap pengguna bangunan, sehingga hasil rancangan yang dihasilkan benar-benar dapat mewadahi seluruh aktifitas yang ada nantinya.

\section{DAFTAR PUSTAKA}

1. Ernest Neufert. 1994. Data Arsitek, Edisi Kedua Jilid 1. Erlangga. Jakarta

2. Ernest Neufert. 1994. Data Arsitek, Edisi Kedua Jilid 2. Erlangga. Jakarta

3. Gunadi, Sugeng. 1989. Pdoman Perancangan Tapak dan Lingkungan. Utama Press. Surabaya.

4. Galllion and Eishner. 1992. Pengantar Perancangan Kota. Erlangga. Jakarta.

5. Hakim, Rustam. 1993. Unsur Perancangan Dalam Arsitektur Lansekap. Penerbit Bumi Aksara. Bandung.

6. Joyce Marcella Laurens. 2004. Arsitektur dan Perilaku Manusia. Grasindo. Jakarta 